\title{
The Spatial Patterning of Mouse Cone Opsin Expression Is Regulated by Bone Morphogenetic Protein Signaling through Downstream Effector COUP-TF Nuclear Receptors
}

\author{
Shinya Satoh, ${ }^{1}$ Ke Tang, ${ }^{2}$ Atsumi Iida, ${ }^{1}$ Mariko Inoue, ${ }^{1}$ Tatsuhiko Kodama, ${ }^{3}$ Sophia Y. Tsai, ${ }^{2}$ Ming-Jer Tsai, ${ }^{2}$ \\ Yasuhide Furuta, ${ }^{4}$ and Sumiko Watanabe ${ }^{1}$ \\ ${ }^{1}$ Department of Molecular and Developmental Biology, Institute of Medical Science, University of Tokyo, Tokyo, 108-8639 Japan, ${ }^{2}$ Department of Molecular \\ and Cellular Biology, Baylor College of Medicine, Houston, Texas 77030, ${ }^{3}$ Research Center for Advanced Science and Technology, University of Tokyo, \\ Tokyo, 153-8904 Japan, and ${ }^{4}$ Department of Biochemistry and Molecular Biology, The University of Texas M. D. Anderson Cancer Center, Houston, Texas \\ 77030
}

Cone photopigments, known as opsins, are pivotal elements and the first detection module used in color vision. In mice, cone photoreceptors are distributed throughout the retina, and short-wavelength $(S)$ and medium-wavelength $(M)$ opsins have unique expression patterns in the retina with a gradient along the dorsoventral axis; however, the mechanisms regulating the spatial patterning of cone opsin expression have not been well documented. The purpose of this study was to define the mechanisms regulating the spatial patterning of cone opsin expression. By analyzing knock-outs for bone morphogenetic protein (BMP) signaling, we found an essential role for BMP in forming cone opsin expression patterns in the retina; however, BMP signaling is activated only transiently in the dorsal half of the retina during early retinal development. Thus, BMP is not likely to play a direct role in opsin gene expression, which starts at a later stage of retinal development. We identified the chicken ovalbumin upstream promoter-transcription factor (COUP-TF) nuclear receptor as a link between BMP and opsin expression. BMP signaling is essential for the correct dorsoventral spatial expression of COUP-TFI and COUP-TFII. Through gain- and loss-of-function analyses, we found that both COUP-TFI and COUP-TFII are required to suppress S-opsin expression in the dorsal retina but that only COUP-TFI plays an essential role in suppressing M-opsin expression in the ventral retina. Based on these findings, we propose a new molecular cascade involving BMP and COUP-TFs that conveys dorsoventral information to direct the expression of cone opsins during retinal development.

\section{Introduction}

Cone photopigments, known as cone opsins, are pivotal elements and the first detection module used in color vision. Several different cone opsins exist, each with a distinct wavelength sensitivity (Dartnall et al., 1983). In vertebrates, the spatial expression pattern of cone opsins across the retina defines the retinal field (the fovea in primates, the visual streak in chickens, or the simple dorsal-ventral and nasal-temporal gradients in fish and rodents) (Bruhn and Cepko, 1996; Szel et al., 1996; Takechi and Kawamura, 2005). However, the mechanisms that regulate the

Received Feb. 25, 2009; revised July 2, 2009; accepted Aug. 17, 2009.

This work was supported by a grant-in-aid from the Ministry of Education, Culture, Sports, Science, and Technology of Japan (S.W.) and by National Institutes of Health Grants DK045641 (M.-J.T.), HL076448 (S.Y.T.), and EY013128 (Y.F.). We are grateful to Drs. Y. Yanagi and S. Kato (University of Tokyo, Tokyo, Japan) for plasmid pcDNA/FLAG-Crx, Drs. T. Imamura (The Japanese Foundation for Cancer Research, Tokyo, Japan) and K. Miyazono (University of Tokyo, Tokyo, Japan) for plasmids pcDNA3/ALK3QD and pCDNA/ALK6QD (constitutively active type Bmp receptors), Dr. C. M. Craft (The Keck School of Medicine of the University of Southern California, Los Angeles, CA) for anti-mCAR antibody, and Perseus Proteomics for providing the antibodies. We thank Dr. N. Watanabe in FACS Core Laboratory (Institute of Medical Science, University of Tokyo, Tokyo, Japan) for his technical support for the sorting. We thank Dr. Mireille Vasseur-Cognet (Inserm, Paris, France) for the discussion.

Correspondence should be addressed to Sumiko Watanabe, Department of Molecular and Developmental Biology, Institute of Medical Science, University of Tokyo, 4-6-1 Shirokanedai, Minato-ku, Tokyo 108-8639, Japan. E-mail: sumiko@ims.u-tokyo.ac.jp.

DOI:10.1523/JNEUROSCI.0951-09.2009

Copyright $\odot 2009$ Society for Neuroscience $\quad$ 0270-6474/09/2912401-11\$15.00/0 expression patterns of these cone opsins during establishment of the retinal field remain poorly understood. In mice, shortwavelength (S) and medium-wavelength $(\mathrm{M})$ opsins have unique expression patterns in the retina, with gradients along the dorsoventral axis, although cone photoreceptors are distributed throughout the entire retina (Applebury et al., 2000).

The molecular players involved in establishing such spatial expression patterns have been reported and include several opsin expression-specific transcription factors, such as thyroid hormone receptor $\beta 2(\mathrm{TR} \beta 2)$, retinoid $\mathrm{X}$ receptor $\gamma(\operatorname{RXR} \gamma)$, and retinoid-related orphan receptor $\beta(\operatorname{ROR} \beta)(\mathrm{Ng}$ et al., 2001; Roberts et al., 2005; Srinivas et al., 2006). However, because these transcription factors are expressed uniformly across the retina, other factors expressed in either the dorsal or ventral retina may regulate the establishment of mouse cone opsin expression patterns.

During early embryogenesis, secreted factors, such as the dorsally localized bone morphogenic protein-4 (BMP4) and the ventrally localized sonic hedgehog within the optic cup, appear to control dorsoventral axis patterning in the developing retina (Jean et al., 1998; Koshiba-Takeuchi et al., 2000; Zhang and Yang, 2001; Murali et al., 2005). Dorsal BMP signaling controls retinal ganglion cell axon projection through establishment of the 
dorsoventral expression pattern of related genes in the retina; however, the involvement of BMP signaling in later retinal differentiation has not been reported.

Nuclear receptors, a large family of ligand-dependent transcription factors, have been shown to be involved in gene networks during embryonic development and in adult physiology. In this study, we focused on chicken ovalbumin upstream promoter transcription factors (COUP-TFs), which are highly conserved members of the steroid/thyroid hormone receptor superfamily. Mice have two COUP-TF homologs, COUP-TFI and COUPTFII, with an exceptionally high degree of homology at the amino acid level (Qiu et al., 1994; Tsai and Tsai, 1997). COUP-TFs are expressed in several organs during embryonic development. COUP-TFI-null mice die perinatally from starvation and dehydration and exhibit defects in neuronal development and axon guidance (Qiu et al., 1997). In contrast, COUP-TFII-null mutants exhibit defects in angiogenesis and heart development and die before embryonic day 10.5 (E10.5) (Pereira et al., 1999). To circumvent this early embryonic lethality, tissue-specific ablation of COUP-TFII has been attempted in several organs (Lee et al., 2004; Bardoux et al., 2005) but not in ocular tissue. The importance of COUP-TFs in retinogenesis was demonstrated initially in Drosophila (Mlodzik et al., 1990). Zebrafish COUP-TF homologs svp [40] and svp [44] are also known to be expressed in the retina (Fjose et al., 1993). However, the role of COUP-TFs in retinal development in vertebrates has not been demonstrated.

\section{Materials and Methods}

Mice and rat. ICR mice and Wister rats were obtained from Japan SLC. Instructions for generating retina-specific BMP receptor conditional knock-out mice, BMPr1a ${ }^{-/ f x} ; B M P r 1 b^{+/-}$;Six3-Cre (BMPR CKO), have been described previously (Murali et al., 2005). For controls, we used retinas from $B M P r 1 a^{+/ f x} ; B M P r 1 b^{+/-} ;$Six3-Cre mice. We maintained these mice in a mixed 129-C57BL/6 background. COUP-TFI-null mice have been described previously (Qiu et al., 1997). In this study, COUP$T F I I^{f x / f x} ; R x$-Cre mice are referred to as retina-specific COUP-TFII-null mice (K. Tang, S. Y. Tsai, and M.-J. Tsai, unpublished observations). For this study, we defined the day that the vaginal plug was detected as E0, and we defined the day of birth as postnatal day 0 (P0). All animal experiments were approved by the animal care committees of the Institute of Medical Science, University of Tokyo, Baylor College of Medicine, and The University of Texas M. D. Anderson Cancer Center.

Cell lines and retinal explant culture. We obtained Y79 cells (Reid et al., 1974) from the Riken Cell Bank (identification number RCB1645) and cultured them in RPMI 1640 medium (Nakarai) supplemented with 10\% fetal calf serum. COS7 cells were grown in DMEM (Nakarai) supplemented with $10 \%$ fetal calf serum. We used a mouse retinal explant culture, which was suitable for testing the effect of environmental tissues on the neural retina because all relevant tissues [e.g., retinal pigment epithelium (RPE), ciliary body, iris, stroma, and cornea] were removed. Retinal explant cultures were prepared as described previously (Tabata et al., 2004). Briefly, retinas derived from mouse embryos, in which dorsoventral orientations were marked by making small incision, were placed on a Millicell chamber filter insert (Millipore Corporation). Filters were placed into a six-well plate containing $1 \mathrm{ml}$ of explant media, comprising 50\% MEM (Invitrogen), $12.5 \mu \mathrm{M}$ HEPES (Invitrogen), 25\% HBSS $(-)$ (Invitrogen), 25\% horse serum (JRH Biosciences), $5.75 \mathrm{mg} / \mathrm{ml}$ glucose, $200 \mu \mathrm{M}$ L-glutamine, and penicillin/streptomycin (Nakarai), and were cultured.

Immunostaining. Immunostaining of frozen-sectioned eyes or retina was done as described previously (Tabata et al., 2004) using the following primary antibodies: mouse monoclonal antibodies against COUP-TFI (1:500; PPMX) and COUP-TFII (1:500; PPMX), and rabbit polyclonal antibodies against S-opsin (1:2000; Millipore Corporation), M-opsin (1: 2000; Millipore Corporation), and mouse cone arrestin (mCAR)
(1:2000; kind gift from Dr. C. M. Craft, The Keck School of Medicine of the University of Southern California, Los Angeles, CA). We visualized the binding of primary antibodies by using appropriate secondary antibodies conjugated to Alexa-488 or Alexa-594 (1:1000; Invitrogen). Whole-mount immunostaining of retinal explant was done with the same protocols of sections, except for the presence of $0.1 \%$ of Triton $\mathrm{X}-100$. The samples were mounted in $50 \%$ glycerol and analyzed using a Carl Zeiss Axioplan.

Quantifying opsin-and $m C A R$-positive cells in frozen-sectioned eyes. To quantify the number of opsin- and mCAR-positive cells in the dorsal and ventral regions of the retina, we used opsin- or mCAR-immunostained frozen sections of meridian line. Under the binocular, we counted positive cells in the region up to $350 \mu \mathrm{m}$ from the tip of the dorsal and ventral peripheries of the retina. We examined retinas from at least three BMPR $\mathrm{CKO}$ and control mice.

Plasmids. cDNAs encoding mouse COUP-TFI, COUP-TFI, ROR $\beta 2$, $B M P 4$, and $T b x 5$ open reading frames (ORFs) were isolated by reverse transcription (RT)-PCR using mouse retinal RNA and then cloned into pGEM-T-Easy vector (Promega). Expression vectors containing COUPTFI (pcDNA/COUP-TFI), COUP-TFII (pcDNA/COUP-TFII), ROR $\beta 2$ (pcDNA/ROR $\beta 2$ ), BMP4 (pcDNA/BMP4), and Tbx5 (pcDNA/Tbx5) cDNA were made by inserting the ORF into the NotI site of pcDNA3.1 (+) (Invitrogen). pcDNA3/FLAG-Crx was kindly provided by Drs. Y. Yanagi and S. Kato (University of Tokyo, Tokyo, Japan). Constitutively active type I BMP receptor-expression plasmids, pcDNA/ ALK3(QD) and pcDNA/ALK6(QD), were kindly provided by Drs. T. Imamura (The Japanese Foundation for Cancer Research, Tokyo, Japan) and K. Miyazono (University of Tokyo, Tokyo, Japan). To construct $S$-opsin-luc and rhodopsin-luc reporters, DNA fragments of mouse S-opsin and mouse rhodopsin promoter/enhancers, which contain 523 and 107 bp upstream region from ATG start codon, respectively, were cloned from mouse genomic DNA by PCR. Then, the fragments were inserted into the pGL3 basic vector (Promega). To construct S-opsin $\Delta-$ luc reporter, which has internal deletion from 251 to 286 of S-opsin promoter/enhancer (supplemental Fig. S5A, available at www.jneurosci. org as supplemental material), internally deleted fragment of S-opsin promoter/enhancer was obtained by PCR-mediated mutagenesis, and cloned into the pGL3 basic vector (Promega). To construct short hairpin RNA (shRNA) vectors, a target sequence of human COUP-TFII corresponding to nucleotide positions 1018-1040 (5'-AAGTCTCAGTGTGCTTTGGAAGA- $3^{\prime}$ ) was selected using siDirect (http://design.rnai.jp/), and that of human COUP-TFI corresponding with nucleotide positions 321343 (5'-AAGTTTCTTCAAGAGGAGCGTCC-3') was selected using Gene Link RNAi Explorer. Basic local alignment search tool analysis showed that no homology existed between each target sequence and any other sequence in the human genome database. For shRNA expression, a double-stranded oligonucleotide covering shRNA sequences was subcloned as described previously (Lin et al., 2009) using pU6 shRNA expression vector (Yamamichi et al., 2005).

Luciferase reporter assay. GeneJuice (Novagen) was used to transfect cells in 12-well dishes with $100 \mathrm{ng}$ of reporter and $300 \mathrm{ng}$ of expression plasmids and/or shRNA-expressing plasmids as indicated in the figures. Total amount of plasmid DNA was adjusted to $1 \mu \mathrm{g}$ by adding pcDNA3.1(+) empty vector (Invitrogen). Cells were harvested at $24 \mathrm{~h}$ (COS7) and $48 \mathrm{~h}$ (Y79) after transfection, and luciferase activity was examined by a luminometer. Values were expressed as relative luciferase activities normalized to protein concentration. Experiments were performed in triplicate, and all assays were repeated at least two times.

Semiquantitative RT-PCR. Total RNA was purified from Y79 cells transfected with expression plasmids using TRIZOL reagent (Invitrogen), and cDNA was synthesized using Superscript II (Invitrogen). All primer sets were tested using different numbers of cycles (18-34 cycles) with rTaq (Takara, Shiga, Japan), and the semiquantitative cycle number was determined for each primer set. PCR products were visualized with ethidium bromide.

Quantitative PCR. Levels of glyceraldehyde-3-phosphate dehydrogenase (G3PDH), long-wavelength (L) opsin, M-opsin, COUP-TFI, and COUP-TFII mRNA were measured by SYBR Green-based quantitative PCR ( $\mathrm{qPCR}$ ), using cDNA prepared from Y79 transfectants. In the case 
of that of S-opsin, hydrolysis probe-based qPCR assays, conventionally called TaqMan assays, was performed using \#18 probe from the universal probe library (Roche Diagnostics). All qPCR analysis was performed using the Roche LightCycler 1.5 apparatus and analyzed by the Second Derivative Maximum Method for quantification (Roche Diagnostics).

Fluorescence-activated cell sorting. Y79 cells were transfected with shRNA expression plasmids together with pCS2+/enhanced green fluorescent protein (EGFP), which was used to mark transfected cells. After $48 \mathrm{~h}$, EGFP-positive cells were sorted by FACSAria (BD Biosciences) and subjected to RT-PCR for monitoring the level of gene expression in the transfected cells.

\section{Results}

Topographical information during early embryogenesis determines opsin expression pattern

During early retinal development, the dorsal and ventral hemispheres of the retina are asymmetrically formed when the optic vesicle undergoes active invagination to form a goblet-shaped optic cup, suggesting that the dorsal and ventral halves of the retina attach differently to adjacent tissues. Therefore, we hypothesized that this interaction creates an asymmetrical environment in the dorsal or ventral hemisphere of the retina to establish unique opsin expression patterns. To test whether environmental tissues of retina are required to establish the spatial patterns of cone opsin expression, we analyzed S-opsin and M-opsin expression in the mouse retina cultivated by a retinal explant culture. In this type of culture, mouse retina at the embryonic stage differentiates into a three-layered structure. The mature retina of ICR mice exhibited a dorsoventral gradient of opsin gene expression, which was also observed in C57BL/6 mice (supplemental Fig. S1, available at www.jneurosci.org as supplemental material). First, we examined whether S-opsin and M-opsins are expressed properly in a retinal explant culture prepared from an E17 ICR mouse. $\mathrm{S}$-opsin was expressed in the ventral half after $14 \mathrm{~d}$ of culture (Fig. 1 , left column, second panel from the bottom), which was consistent with previous results from the P0 retina (Wikler et al., 1996). Although previous studies failed to observe M-opsin expression in retinal explant cultures (Soderpalm et al., 1994; Wikler et al., 1996), we observed M-opsin expression with a clear dorsal-to-ventral gradient as seen in vivo (Applebury et al., 2000) (Fig. 1, right column, second panel from the bottom). Next we examined the time course of S-opsin and M-opsin expression. $\mathrm{S}$-opsin and M-opsins were first detected after 3 and $7 \mathrm{~d}$ of culture, respectively, which is consistent with the in vivo observation that $\mathrm{S}$-opsin expression starts earlier than $\mathrm{M}$-opsin expression. The experiment was then repeated using a retinal explant prepared from an E12 retina. Again, a unique dorsoventral gradient of S-opsin and M-opsin expression was established during culture (Fig. 1, bottom panels). These results suggest that positional information to regulate opsin expression is imposed by E12 and is maintained intrinsically in the retina during development.

\section{BMP signaling regulates expression of opsin in dorsal cones}

Because dorsally localized BMP signaling is known to control retinal dorsoventral patterning, we hypothesized that determination of opsin expression patterns is also under the control of BMP signaling in the early developing retina. To test this possibility, we used retina-specific BMPR CKO (BMPr1 $a^{-/ f x} ; B M P r 1 b^{+/-}$;Six3Cre) mice and control littermates (BMPrla ${ }^{+/ f x} ; B M P r 1 b^{+/-}$; Six3-Cre) (Murali et al., 2005). BMPR CKO is a heterozygous knock-out of BMPR $1 a$ and $1 b$, with the other allele of BMPR $1 a$ deleted by Six 3 promoter-driven Cre recombinase, which begins to exhibit activity in the retina at E9.0-E9.5 (Furuta et al., 2000). High levels of phosphorylated Smad1/5/8, which directly reflects

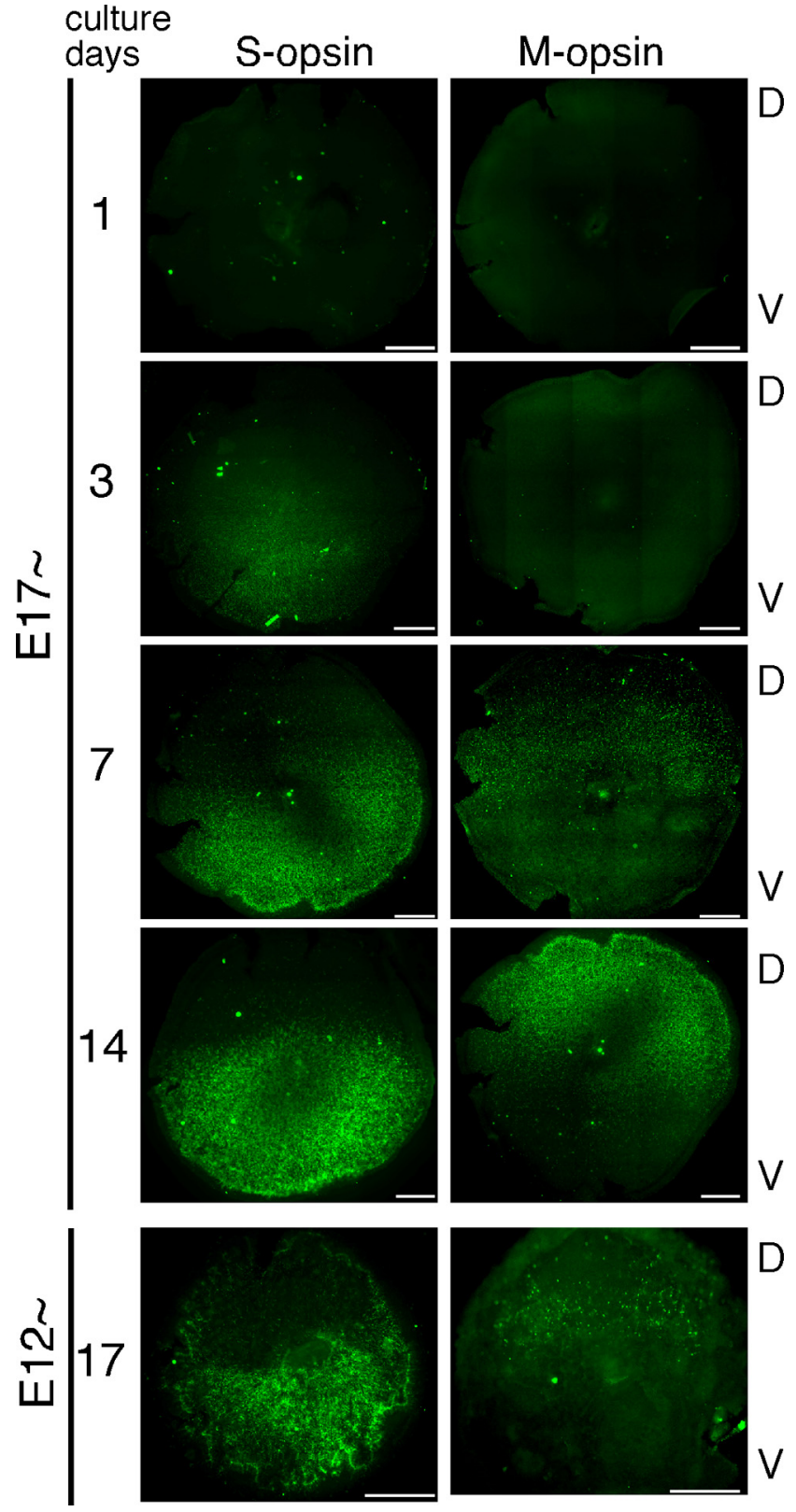

Figure 1. Opsin expression patterns in retinal explant cultures. Retinal explants prepared from E17 or E12 mice were cultured for the indicated number of days. Whole-mount immunostaining was performed for S-opsin and M-opsin expression, and the signals were visualized using secondary antibodies conjugated to Alexa-488 (green). Photos were taken from the bottom of the explants (ONL). The pictures show the top of the dorsal side. D, Dorsal; V, ventral. Scale bars, $500 \mu \mathrm{m}$.

active BMP signaling, were observed in the dorsal retinas of wildtype mice but not of BMPR CKO mice at E11.5, suggesting that BMPr1a is lost between E9.0 and E11.5 in the BMPR CKO mouse retina (Murali et al., 2005). BMPR CKO mice exhibit characteristic defects in retinal dorsoventral polarity without overt morphological defects in the eye (Murali et al., 2005). We examined cone opsin expression pattern in BMPR CKO mice at the adult stage by immunostaining using frozen-sectioned eyes. In the retina of the control mice, the number of cones expressing S-opsin in the dorsal periphery was approximately half that in the ventral periphery (Fig. $2 A$, bottom left panels, $C$ ); the intensity and number of M-opsin-expressing cells in the dorsal area was higher than that in the ventral area (Fig. $2 \mathrm{~B}$, bottom left panels, $D$ ). In BMPR 
A
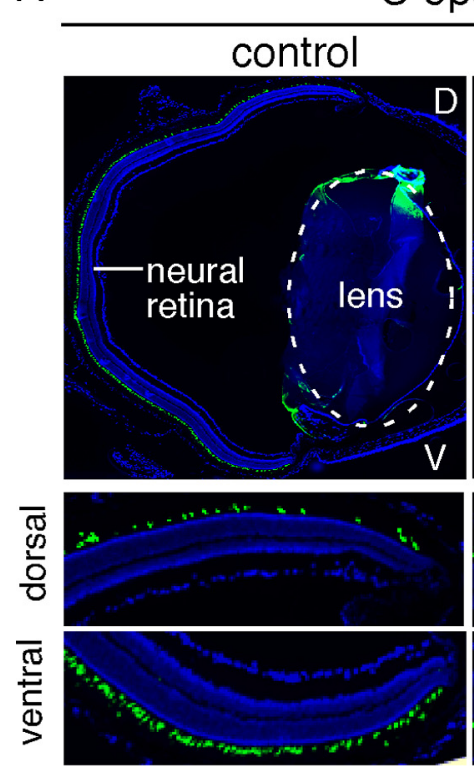

C

S-opsin+ cells (No/field)

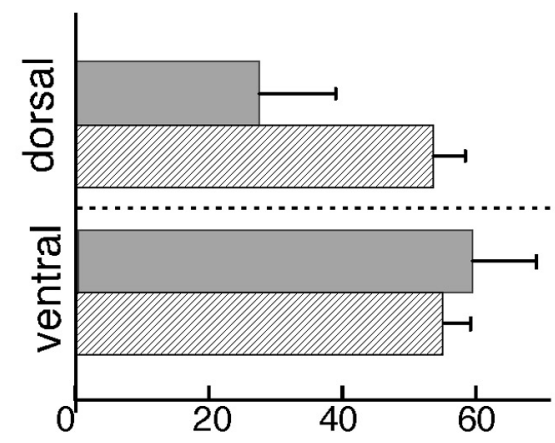

B
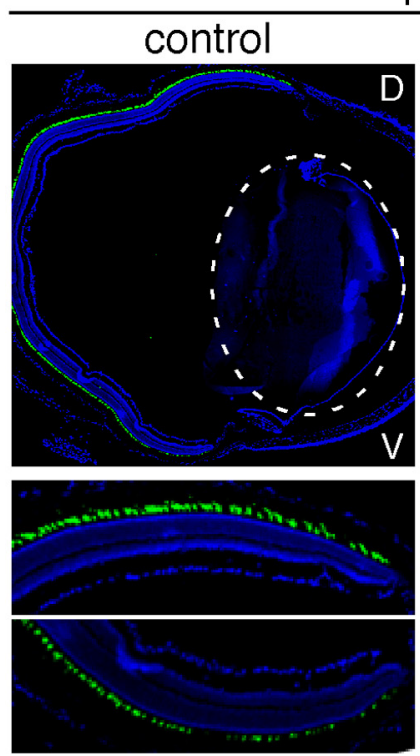

E

M-opsin+ cells (No/field)

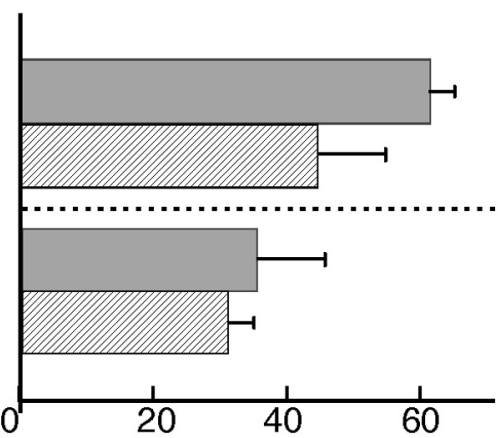

M-opsin

D
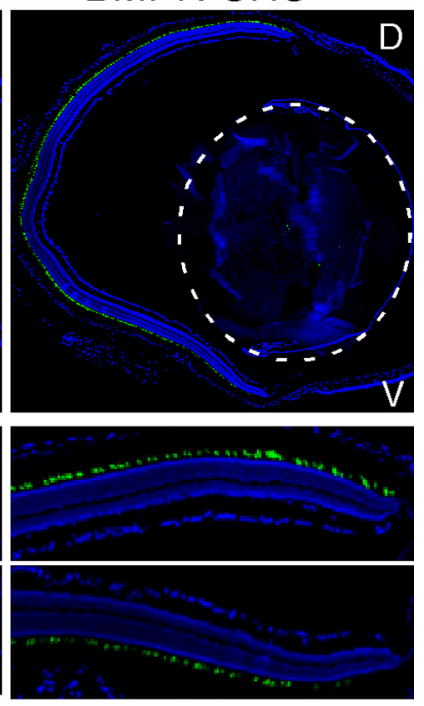

cone cells

(No of mCAR+/filed)

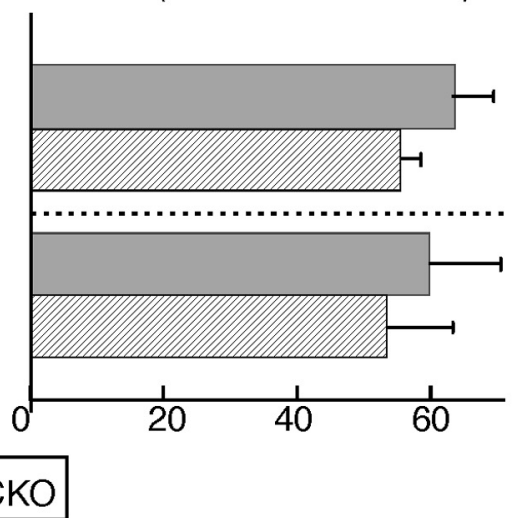

Figure 2. S-opsin and M-opsin expression in BMPR CKO (BMPr1a ${ }^{-/ f x} ; B M P r 1 b^{+/-}$;Six3-Cre) mouse retina. $A, B$, Frozen-sectioned eyes from adult control or BMPR CKO mice were immunostained with anti-S-opsin $(\boldsymbol{A})$ and anti-M-opsin $(\boldsymbol{B})$ antibodies; the signals were visualized using a secondary antibody conjugated to Alexa-488 (green). The nuclei were visualized by $4^{\prime}, 6^{\prime}$ diamidino-2-phenylindole (DAPI) staining (blue). The middle and bottom are enlarged views of the dorsal and ventral periphery. The control retinas were taken from $B M P r 1 a^{+/ / x} ; B M P r 1 b^{+/-}$; Six3-Cre mice. D, Dorsal; $V$, ventral. C $E$, Immunostaining for mCAR (pan-cone cell marker) was performed using frozen-sectioned eyes from adult control and BMPR CKO mice. The number of S-opsin-positive ( $($ ), M-opsin-positive (D), and mCAR-positive $(\boldsymbol{E})$ cells in the peripheral area (from the peripheral tip to $350 \mu \mathrm{m}$ inside of the retina) on the dorsal and ventral sides was quantified ( $n=3$ for each genotype).

CKO mice, S-opsin expression in dorsal cones increased to approximately the level observed in ventral cones (Fig. $2 \mathrm{~A}$, bottom right panels, $C$ ), whereas both the number of cells expressing $\mathrm{M}$-opsin and the level of M-opsin expression decreased (Fig. 2 B, bottom right panels, $D$ ). The number of cone cells, indicated by the number of mCAR/pan-cone cell marker-positive cells, did not differ between the control and BMPR CKO mice in the dorsal and ventral peripheries (Fig. $2 E$ ). These data suggest that the attenuation of BMP signaling in BMPR CKO mice causes S-opsin and $\mathrm{M}$-opsins to be expressed improperly in the dorsal cone cells without affecting the number of cone cells.

\section{Dorsoventral expression patterns of COUP-TFI and COUP-TFII}

BMP signaling is transiently activated in the dorsal retina at approximately E11, whereas expression of the S-opsin and M-opsin genes begins at approximately E13 and P6, respectively (Fei, 2003; Applebury et al., 2007). Therefore, intermediate mole- cule(s) that mediate BMP signaling may serve to establish the positional information necessary for directing opsin expression at a later stage. We focused on the orphan nuclear receptors COUP-TFI and COUP-TFII as candidate downstream effectors of dorsal BMP signaling, because dorsoventral expression of these factors was observed in the retina. We examined the detailed expression patterns of COUP-TFs by immunostaining (Fig. 3). COUP-TFI expression was detected throughout the optic vesicle at E9, but the intensity was slightly higher in the ventral half of the optic vesicle (Fig. 3A, left, arrows). At E11 and E14, strong expression of COUP-TFI was maintained in the ventral half of the retina, whereas its expression levels in the dorsal half were markedly lower (Fig. 3A). After birth, retinal expression of COUP-TFI was maintained throughout the ganglion cell layer (GCL) and the inner nuclear layer (INL); we also observed a dorsoventral expression gradient but with a weak incline.

In sharp contrast to COUP-TFI, the distal region on the dorsal side of the optic vesicle strongly expressed COUP-TFII (Fig. 3B, 
A
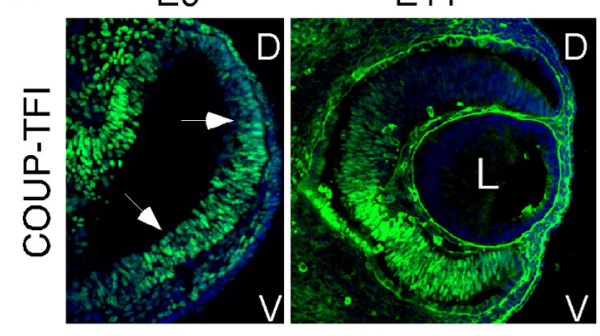

B

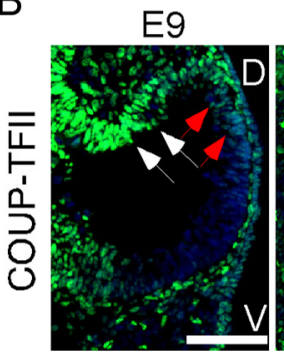

E11

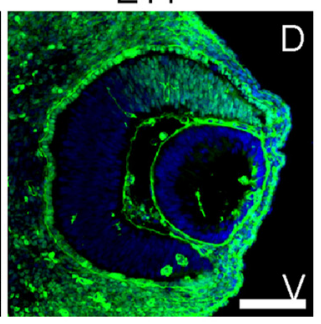

E14

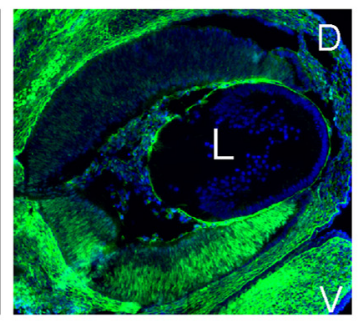

P1
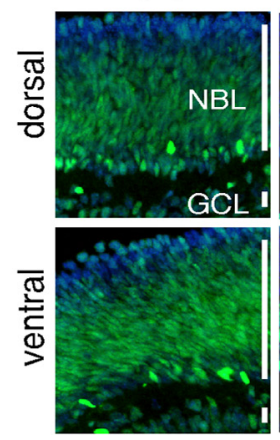

E14
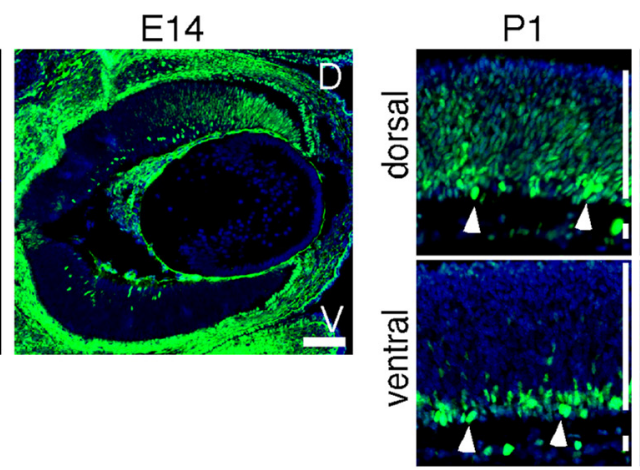

P8
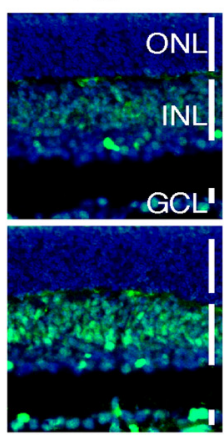

P8

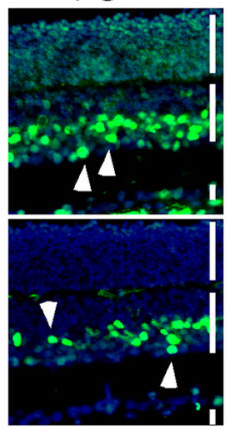

Adult
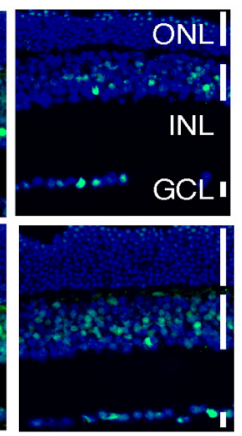

Adult

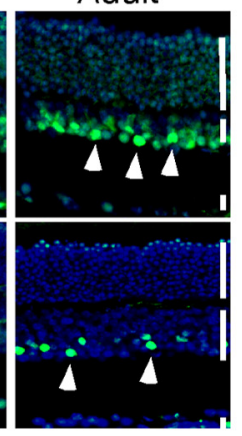

C

E11

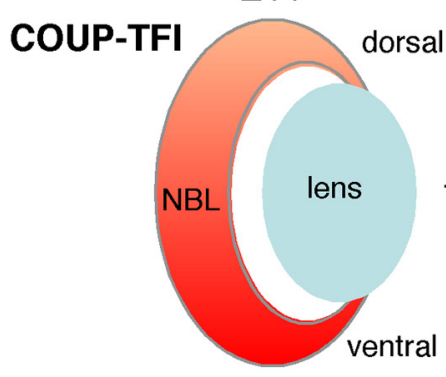

Adult

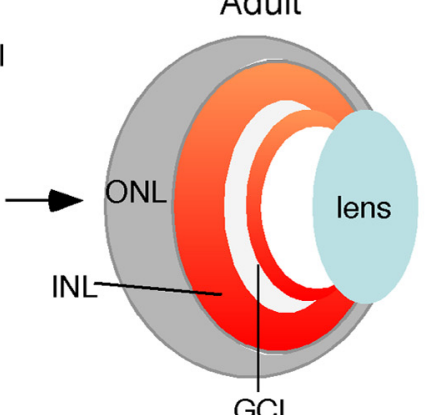

E11

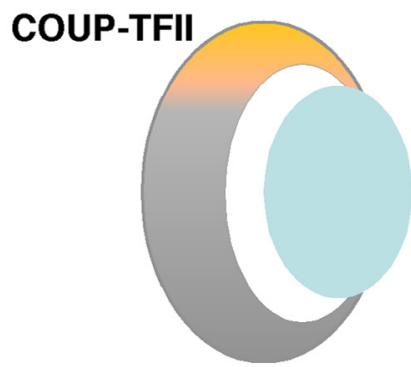

Adult

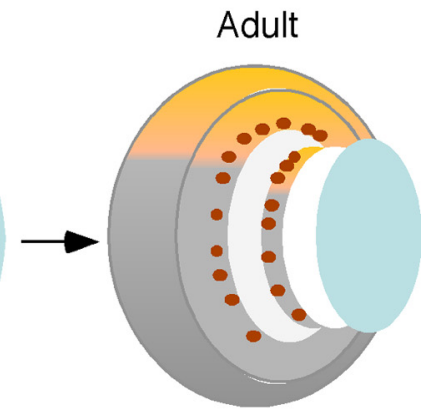

Figure 3. Expression of COUP-TFl and COUP-TFII during mouse retinal development. $A, B$, Frozen-sectioned eyes from wild-type mice at the indicated developmental stage were immunostained with anti-COUP-TFI and -COUP-TFIl antibodies (green). The nuclei were stained with DAPI (blue). The arrows and arrowheads in the panels are described in Results. Scale bars, $100 \mu \mathrm{m}$. D, Dorsal; V, ventral. C, D, Schematic representation of the expression patterns of COUP-TFI (red, C) and COUP-TFII (yellow and brown, D). L, Lens; NBL, neuroblastic layer.

left, red arrows) and presumptive RPE (Fig. 3B, left, arrows) at E9. We observed that COUP-TFII was expressed exclusively at E11 in the dorsal area, which is consistent with previous data (McCaffery et al., 1999), and that this expression persisted until adulthood (Fig. $3 B$ ). In the INL, we observed scattered cells expressing strong COUP-TFII at E14, and these cells became restricted to the INL as the retina matured (Fig. $3 B$, arrowheads). Double immunostaining for several retinal subtype markers, such as $\mathrm{HuC} / \mathrm{HuD}$ and glycine transporter 1 , suggested that the positive cells were amacrine cells (data not shown). The third member of the COUP-TF family, COUP-TF $\gamma$ (COUP-TFIII) (Jonk et al., 1994), is evolutionarily distant from COUP-TFI and COUP-TFII, which exhibit exceptionally high homology; in contrast, the primary structures of COUP-TF $\gamma$ and COUP-TFI are only $60 \%$ identical. RT-PCR experiments revealed expression of COUP-TF $\gamma$ mRNA in developing mouse retina, but immunostaining experiments failed to reveal COUP-TF $\gamma$ protein expression in embryonic retina (data not shown). Results of additional studies also suggest that COUP-TF $\gamma$ plays a role distinct from those of COUP-TFI and COUP-TFII in retinal development. Summaries of the COUP-TFI and COUP-TFII expression patterns are given in Figure 3, $C$ and $D$.

\section{Perturbed dorsoventral expression patterns of COUP-TFI and COUP-TFII in BMPR CKO mouse retina}

We examined whether BMP signaling regulates the unique dorsoventral expression patterns of COUP-TFI and COUP-TFII in the retina. We used immunostaining to examine COUP-TFs expression in the retina of E14 BMPR CKO mice (Fig. 4). COUPTFI expression in the dorsal region was enhanced in BMPR CKO mice; however, on the ventral side, no apparent difference was observed with the control littermate retina (Fig. $4 A, B$ ). In contrast, we found that COUP-TFII expression on the dorsal side was completely abolished in BMPR CKO mice (Fig. 4C,D), whereas strong amacrine cell staining in the central region of the retina was present in both BMPR CKO and control animals (Fig. 4C, arrowheads). 


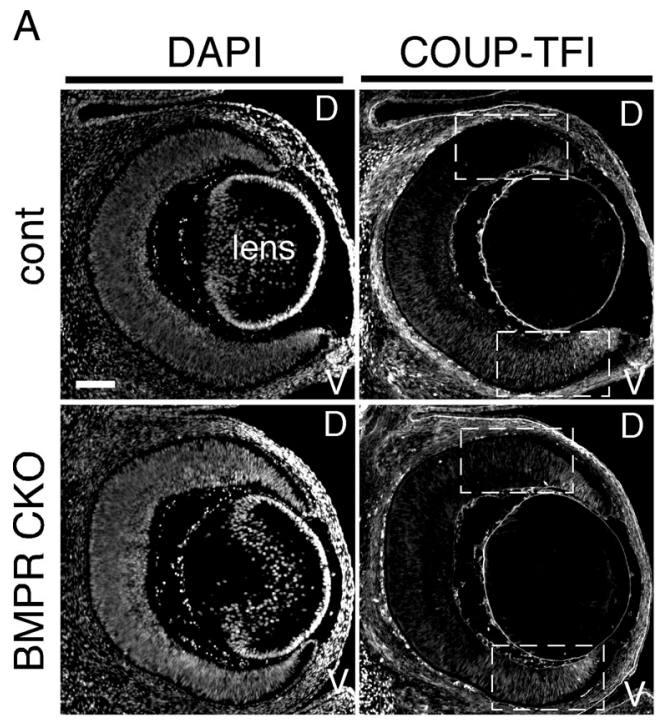

B

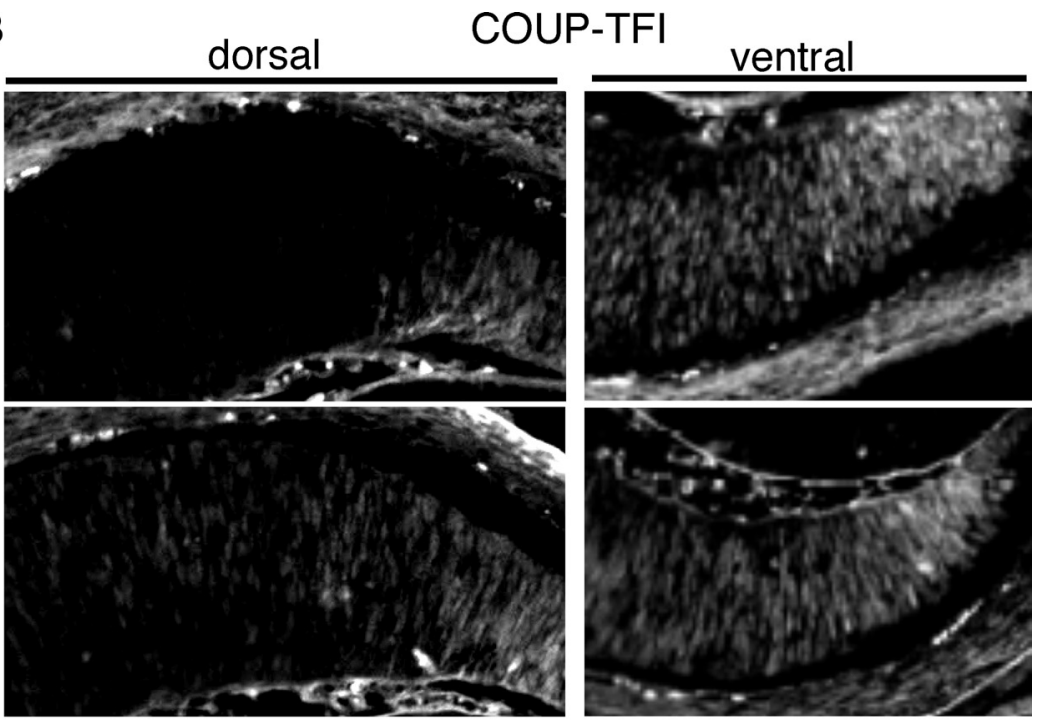

C
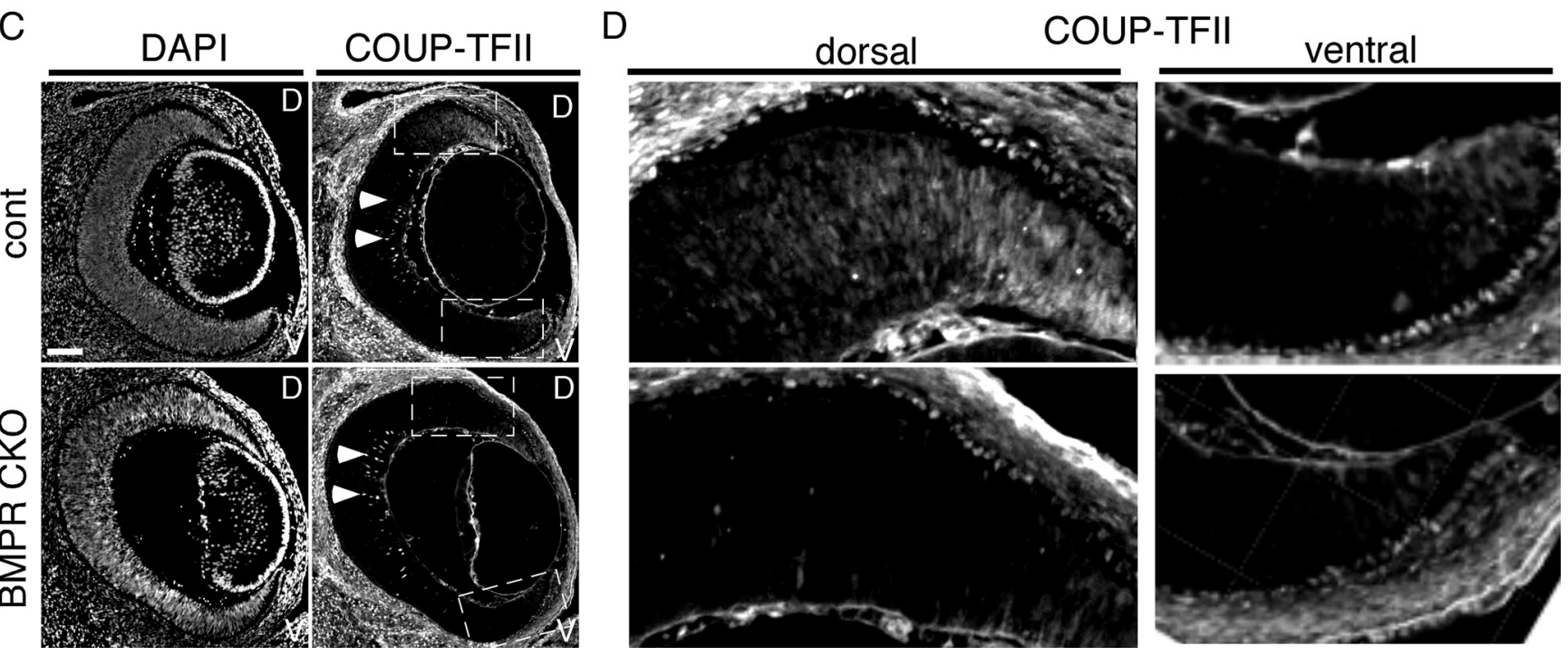

Figure 4. Expression of COUP-TFs in BMPR CKO mouse retina. $\boldsymbol{A}-\boldsymbol{D}$, Frozen sections of control and BMPR CKO mouse eyes at E14.5 were immunostained with anti-COUP-TFI $(\boldsymbol{A}, \boldsymbol{B})$ and anti-COUP-TFII $(\boldsymbol{C}, \boldsymbol{D})$ antibodies. The panels in the left column show nuclear staining by DAPI. $\boldsymbol{B}$ and $\boldsymbol{D}$ are enlarged views of the dorsal and ventral regions in the right panels of $\boldsymbol{A}$ and $\boldsymbol{C}$. The regions are indicated by dashed boxes. D, Dorsal; $V$, ventral. Scale bars: $A, C, 100 \mu \mathrm{m}$.

Altered expression of cone opsin in COUP-TF null mouse retina

Based on these results, we hypothesized that BMP signaling regulates the expression of opsins by regulating COUP-TF expression, at least on the dorsal side. Thus, we next used COUP-TFI-null (Qiu et al., $1997)$ and retina-specific COUP-TFII-null mice (COUP-TFII ${ }^{f x / f x}$ : $\mathrm{Rx}-\mathrm{Cre}$ ) to examine whether COUP-TFI and COUP-TFII are required for normal expression pattern of opsins in vivo (Fig. 5A,B). Immunostaining revealed that the expression of both S-opsin and $\mathrm{M}$-opsin was severely perturbed in the COUP-TFI-null mice. COUP-TFI-null mice expressed S-opsin at nearly equal levels on the dorsal and ventral sides of the retina, whereas the expression of $\mathrm{M}$-opsin was upregulated on the ventral side, resulting in loss of expression gradient on the dorsoventral axis. The retina-specific COUP-TFII-null mice expressed upregulated S-opsin on the dorsal side, although the expression was not as strong as it was in the COUP-TFI-null mice; these mice expressed a normal M-opsin pattern. These data indicated that COUP-TFI and COUP-TFII are necessary to suppress S-opsin in the dorsal cones, whereas only COUP-TFI is required to suppress $\mathrm{M}$-opsin in the ventral cones.

\section{COUP-TFs suppress $S$-opsin}

To gain more mechanistic insights into transcriptional control of cone opsin genes, we performed a series of experiments using the Y79 human retinoblastoma and COS7 monkey fibroblast cell lines. The $0.5 \mathrm{~kb}$ mouse $S$-opsin enhancer/promoter, which is activated by specific Crx and ROR $\beta 2$ binding (Srinivas et al., 2006), was conjugated with luciferase (S-opsin-luc). S-opsin-luc was weakly activated by the expression of Crx or ROR $\beta 2$; moreover, we observed a synergistic effect in Y79 cells (Fig. 6A) and COS7 cells (supplemental Fig. S2, available at www.jneurosci.org as supplemental material). COUP-TFI or COUP-TFII strongly suppressed luciferase activity induced by $\mathrm{Crx}$ and $\operatorname{ROR} \beta 2$. COUP-TFI or COUP-TFII suppressed Crx-induced luciferase activity (Fig. $6 \mathrm{~B}$, arrows) but slightly enhanced the activity induced by ROR $\beta 2$ (Fig. $6 B$, arrowheads). We confirmed that forced COUP-TF expression did not decrease the level of Crx or ROR $\beta 2$ expression by Western blotting (supplemental Fig. S2, available at www.jneurosci.org as supplemental material). The COUP-TFs did not suppress Crx- and Nrl-induced luciferase activity driven by the mouse rhodopsin enhancer/promoter, 
A

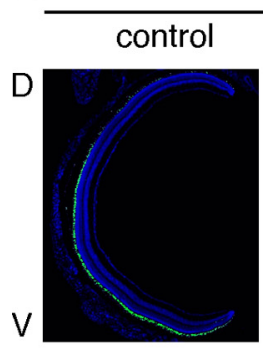

D

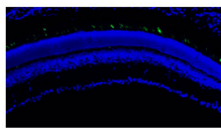

V

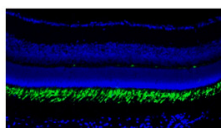

B

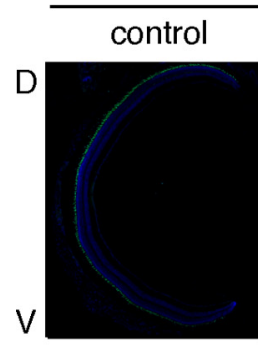

D
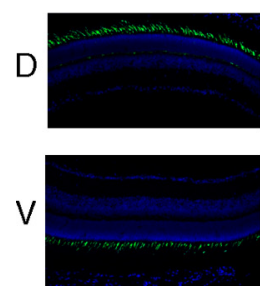

S-opsin
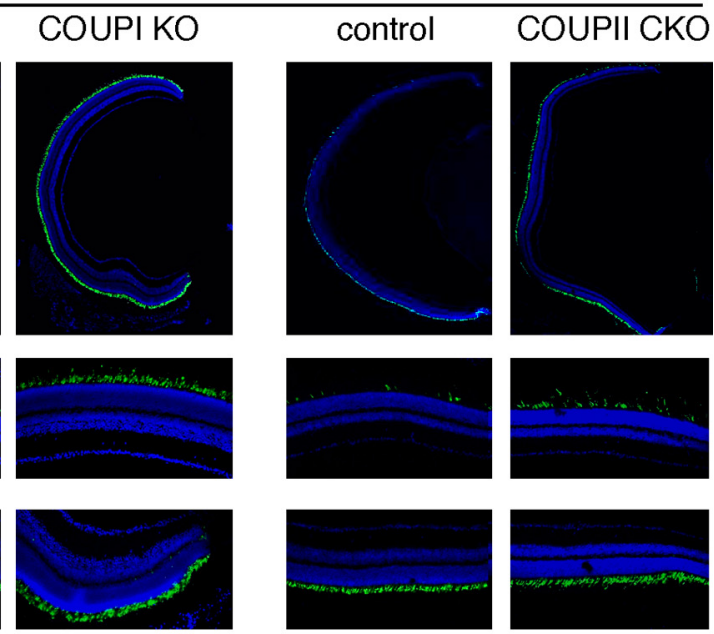

M-opsin
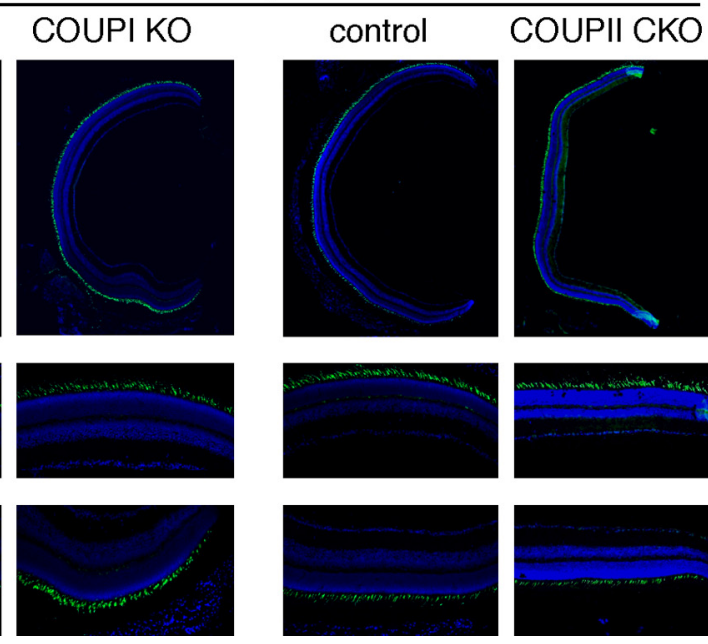

Figure 5. Expression of S-opsin and M-opsin in COUP-TFI-null and retinal-specific COUP-TFII-null mouse retina. $\boldsymbol{A}, \boldsymbol{B}, \mathrm{S}$-opsin $(\boldsymbol{A})$ and $M$-opsin ( $B$ ) expression was examined by immunostaining using frozen-sectioned eyes from COUP-TFI knock-out mice (COUPI KO) at P23 and COUP-TFIl retina-specific knock-out mice (COUP-TFII ${ }^{f / f x} ;$; RX--Cre; COUPII CKO) at 3 months of age. The signals were visualized using a secondary antibody conjugated to Alexa-488 (green). The nuclei were visualized by DAPI staining (blue). The middle and bottom are enlarged views of the dorsal and ventral periphery. The control samples were taken from each littermate of the COUP-TFI KO and COUP-TFII CKO mice. D, Dorsal; V, ventral.

which contains a 107 bp upstream region (Chen et al., 1997) (Fig. $6 C$ ). These results suggest that COUP-TFs specifically suppress $S$-opsin at the level of transcription within the $S$-opsin promoter, probably through the suppression of Crx activity. Moreover, the suppressive effect depends on the promoter context, based on our observation that neither COUP-TF suppressed the activity of the rhodopsin promoter.

Y79 is a human retinoblastoma cell line, and forced Crx expression induces S-opsin (human blue opsin) (Peng and Chen, 2007). Therefore, we examined how COUP-TFs affect human $S$-opsin expression by looking at the expression of endogenous $S$-opsin mRNA via semiquantitative and quantitative RT-PCR. As we expected, Crx increased the level of endogenous $S$-opsin expression in Y79 cells; however, the effect was abolished by COUP-TFI or COUP-TFII (Fig. 6D).

\section{Knockdown of COUP-TF augmented $S$-opsin}

We examined the effects of the shRNA-mediated knockdown of COUP-TFI or COUP-TFII on S-opsin expression in Y79 cells.
The expression of shRNAs against either human COUP-TFI or COUP-TFII effectively and specifically suppressed the endogenous mRNA expression of COUP-TFI or COUP-TFII, respectively (Fig. $6 E$ ). In Y79 cells, Crx-induced S-opsin was enhanced by the knockdown of either COUPTFI or COUP-TFII (Fig. 6E), confirming that both COUP-TFs have suppressive effects on S-opsin.

Next we examined whether the basal level of $S$-opsin expression is regulated by endogenous COUP-TFI or COUP-TFII in the absence of exogenous Crx. Unfortunately, we were unable to draw any conclusions from the results shown in Figure $6 \mathrm{E}$ because not all of the cells were transfected with the shRNA construct. Therefore, we used cells cotransfected with an EGFP expression plasmid to purify the shRNA-transfected cells by cell sorting. In this way, we detected clear augmentation of $S$-opsin after treating with shRNAs for COUP-TFI or COUP-TFII (Fig. $6 F$ ), suggesting that COUP-TFI and COUP-TFII also regulate the basal level of $S$-opsin.

Finally, we analyzed the effect of BMP signaling on endogenous L-opsin, M-opsin, and COUP-TFI in Y79 cells (Fig. 6G). Humans have a third opsin gene (L-opsin) that arose through duplication, resulting in a tandem array of L-opsin/M-opsin genes on the X chromosome. BMP4 enhanced L-opsin and M-opsin but suppressed COUP-TFI. These results are consistent with our in vivo data showing that BMP signaling had negative and positive effects on the expression of COUPTFI and $M$-opsin, respectively.

\section{Discussion}

Initially, we thought that the unique dorsoventral expression patterns of S-opsin and $\mathrm{M}$-opsin were achieved through their interaction with the surrounding tissues during development. However, we found that isolated retinas could establish the correct spatial expression patterns for S-opsin and $\mathrm{M}$-opsin in vitro even at E12, suggesting that the positional information required for proper opsin expression is established before E12 and that the surrounding tissues of the retina are dispensable in maintaining the spatial opsin expression pattern.

We found that BMP signaling, although essential for opsin expression patterning, is not the only signal that regulates opsin expression; we observed that opsin expression in BMPR CKO mice was perturbed but not abolished. Although researchers have thoroughly characterized retinal projections are regulated along the dorsoventral axis by BMP in the early stages of retinal development (Koshiba-Takeuchi et al., 2000; Trousse et al., 2001; Murali et al., 2005), little is known about the role of BMP in the later stages of retinal development, especially in retinal celltype specification. The activation of Smad1/5/8 in the dorsal retinas of BMPR CKO mice is lost at E11.5 (Murali et al., 2005). We detected alterations in the expression of COUP-TF and opsin in 


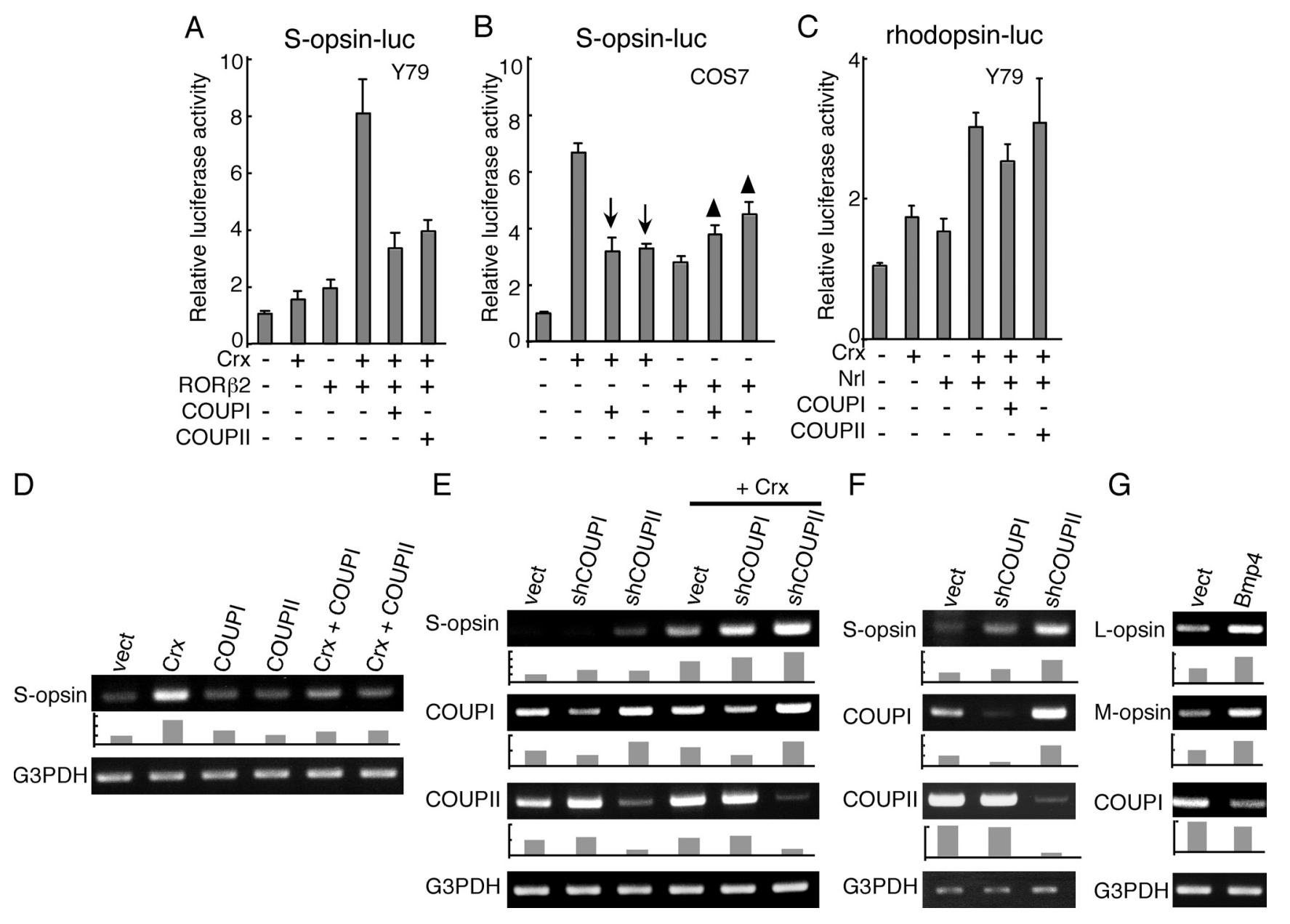

Figure 6. Effects of changes in COUP-TF expression on opsin expression. $\boldsymbol{A}-\boldsymbol{C}$, Transient reporter assays were performed using Y79 $(\boldsymbol{A}, \boldsymbol{C})$ and $\operatorname{COS7}(\boldsymbol{B})$ cells. The cells were transiently transfected with plasmids as indicated in the figure and cultured for $24 \mathrm{~h}$ (COS7) or $48 \mathrm{~h}$ (Y79). Luciferase activity was then examined. The luciferase reporters were S-opsin--Iuc for $\boldsymbol{A}$ and $\boldsymbol{B}$ and $r$ hodopsinluc for $\boldsymbol{C}$. The arrows and arrowheads in $\boldsymbol{B}$ are discussed in Results. D-F, Y79 cells were transiently transfected with the indicated plasmids, and, after $48 \mathrm{~h}$ of culture, total RNA was extracted and used for CDNA synthesis. In $\boldsymbol{F}$, Y79 cells transfected with the indicated plasmid along with an EGFP expression plasmid were purified by cell sorting based on EGFP expression, and total RNA was extracted for cDNA synthesis. Semiquantitative (top) and quantitative (bottom) PCR was done using primers for S-opsin, COUP-TFI (COUPI), COUP-TFII (COUPII), and G3PDH. G, Y79 cells were transfected with a control vector or BMP4 expression plasmid and cultured for $48 \mathrm{~h}$. The cells were then harvested, and the expression of L-opsin, M-opsin, COUP-TFI, and G3PDH was examined by semiquantitative (top) and quantitative (bottom) RT-PCR. The results of quantitative PCR were shown by the relative expression level of each gene normalized to G3PDH. COUPI, COUP-TFI; COUPII, COUP-TFII.

Smad4 retina-specific knock-out mice (data not shown), supporting the notion that canonical BMP signaling through Smad is important for COUP-TF and opsin regulation. Tbx5 is a major downstream target of BMP signaling that leads to the activation and repression of dorsal- and ventral-specific genes, respectively (Koshiba-Takeuchi et al., 2000). However, we did not detect the modulation of COUP-TF expression in response to Tbx5 (supplemental Fig. S3A, available at www. jneurosci.org as supplemental material), leading us to speculate that BMP uses a Tbx5-independent signaling cascade to regulate COUP-TFs expression. BMPR1b, one of the type I BMP receptors, is expressed exclusively in the ventral retina during the embryonic period (Liu et al., 2003). In BMPR1b knock-out mice, the axon pathfinding of ventrally localized retinal ganglion cells is perturbed, whereas the expression pattern of both cone opsins appears to be normal (Liu et al., 2003); this research indicates that ventral BMP signaling through BMPR1b may not significantly affect cone opsin patterning.

COUP-TFs are expressed as early as E9, which is almost the same stage at which BMP4 expression begins (Furuta and Hogan, 1998), suggesting that BMP directly affects COUP-TF expression.
Although BMPR CKO mice showed a loss of COUP-TFII expression in the dorsal retina, activating BMP-related signaling in response to the expression of a constitutively active form of BMPR1a or BMPR1b, or adding recombinant BMP4 into Y79 or retinal explants did not stimulate COUP-TFII expression (supplemental Fig. S3 $B, C$, available at www.jneurosci.org as supplemental material). We observed that COUP-TFI was suppressed only when BMP4 was expressed in Y79 cells. Therefore, BMP signaling is essential but may not be sufficient for the induction of COUP-TFII expression. Alternatively, BMP may act in a stageand/or cell-specific manner or may simply maintain the expression pattern of COUP-TFII without affecting the initiation of transcription. The latter notion is supported by the observed divergent responses of COUP-TFI and COUP-TFII to the loss of BMP signaling. Currently, we are investigating the mechanism how BMP signaling regulates the expression of COUP-TFs using the isolated promoter regions of COUP-TFI and COUP-TFII.

Retinoids stimulate the expression of COUP-TFI in the WERI-Rb1 human retinoblastoma cell line (Li et al., 2003), and we also found that adding retinoic acid to Y79 cells induced COUP-TFI but not COUP-TFII (supplemental Fig. S4A, available at www.jneurosci.org as supplemental material). The reti- 

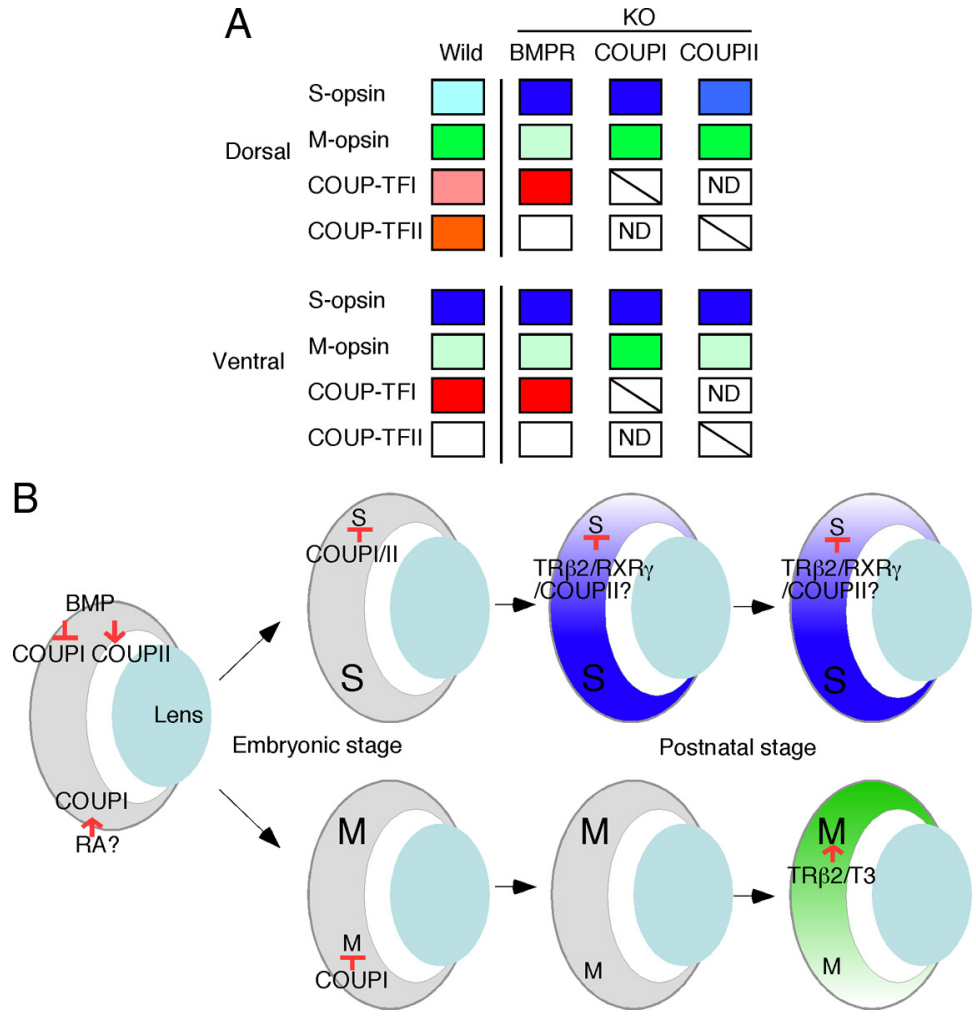

Figure 7. Model of the regulation of opsin spatial expression in mice. $A$, Summary of opsin and COUP-TF expression in the mutant mice used in this study. The depth of each color indicates the intensity of expression for each gene. ND, Not determined. $B$, Schematic representation of the regulation of opsin expression. COUPI, COUP-TFI; COUPII, COUP-TFII.

noic acid signaling pathway is involved in retinal dorsoventral patterning (Marsh-Armstrong et al., 1994; Hyatt et al., 1996; McCaffery et al., 1999), and retinoic acid synthetases, such as Raldh1 and Raldh3, are differentially distributed along the dorsoventral axis of the retina (Li et al., 2000; Mic et al., 2000). Therefore, ventral retinoic acid may positively regulate COUP-TFI expression.

The nonoverlapping and temporally distinct expression patterns of COUP-TFI and COUP-TFII in various organs during development (Lu et al., 1994; Qiu et al., 1994; Tang et al., 2005; Suh et al., 2006) suggest that the expression of COUP-TFI and COUP-TFII is regulated independently. However, the complementary expression patterns of COUP-TFI and COUP-TFII in the retina suggest reciprocal suppressive regulation of their expression. Indeed, the downregulation of COUP-TFII in Y79 cells led to a slight enhancement in COUP-TFI expression, supporting this notion; COUP-TFII was not enhanced after the downregulation of COUP-TFI. Furthermore, overexpression of COUP-TFI or COUP-TFII did not alter the level of COUP-TFII or COUPTFI, respectively (supplemental Fig. $4 B$, available at www. jneurosci.org as supplemental material). Because complementary COUP-TFI and COUP-TFII expression in the retina was observed only at the embryonic stage, such reciprocal regulation may be a retina stage-specific phenomenon.

When S-opsin expression began at approximately E13, weak COUP-TFI expression and strong COUP-TFII expression were observed on the dorsal side of the retina. The overexpression of COUP-TFI or COUP-TFII indicated that they are capable of suppressing S-opsin, and our results in COUP-TFI/COUP-TFII knock-out mice indicate that both COUP-TFI and COUP-TFII are essential to suppress S-opsin (Fig. 7A). Therefore, we surmise that the lack of COUP-TFII expression in the dorsal retinas of
BMPR CKO mice resulted in increased $\mathrm{S}$-opsin expression in the dorsal cone cells, although COUP-TFI expression increased. Because COUP-TFI ceases in the cells of the outer nuclear layer (ONL) after birth, the cooperative suppression of S-opsin by COUP-TFs may not be involved in maintaining the suppression of S-opsin in dorsal cone cells. $\mathrm{TR} \beta 2$ and RXR $\gamma$ are expressed in postmitotic cone cells, and the enhanced expression of S-opsin in the dorsal retina was observed in TR $\beta 2$ and $R X R \gamma$ knockout mice (Ng et al., 2001; Roberts et al., 2006). However, both proteins are uniformly expressed in the retina, so it is unclear how they suppress S-opsin only on the dorsal side. Because COUP-TFI and COUP-TFII expression began earlier than $\mathrm{TR} \beta 2$ and $\operatorname{RXR} \gamma$ expression, COUP-TFs may determine opsin expression pattern, and $\mathrm{TR} \beta 2$ and $\operatorname{RXR} \gamma$ may directly or indirectly maintain the dorsal suppression of S-opsin (Fig. 7B). Our analysis of COUP-TFI and COUPTFII expression in the retina at an early developmental stage shows that expression is not restricted to cone or cone progenitor cells. We do not think that the expression of COUP-TFs is limited to cells of the cone lineage, because COUP-TFs might function only when opsin gene activation modules are present.

Recently, COUP-TFI and COUP-TFII were shown to function cooperatively in neural stem/progenitor cells for the acquisition of gliogenic competence (Naka et al., 2008). We observed the unique expression of COUP-TFs in certain retinal cell subtypes in the INL during late development, suggesting that COUPTFs play cooperative roles in determining the fate of retinal progenitor cells in the retina.

COUP-TFs have been reported to act as transcriptional repressors by either recruiting a corepressor, such as N-CoR (nuclear receptor corepressor) or SMRT (silencing mediator of retinoic acid and thyroid hormone receptor), or competing for DNA binding with a transcriptional activator (Tsai and Tsai, 1997). In the latter case, a putative binding site for COUP-TF has been reported (Tsai and Tsai, 1997), and we found putative binding sites for COUP-TF within the S-opsin enhancer used in our study; however, the deletion of these sites did not affect the suppressive effect of COUP-TFs (supplemental Fig. S5, available at www.jneurosci.org as supplemental material). Conversely, opsin gene regulation by COUP-TFs via epigenetic effects is feasible. In fact, DNA methyltransferase $3 \mathrm{a}$ and $3 \mathrm{~b}$ were identified as interacting partners of COUP-TFI, and their role in the regulation of target genes by COUP-TFI has been suggested previously (Gallais et al., 2007). Because COUP-TFI and COUP-TFII are highly conserved, similar interactions may also be possible for COUP-TFII. We believe that this may also explain why the established opsin expression pattern persists until adulthood when COUP-TFI is not expressed in mature cone cells.

Finally, we asked whether the unique expression patterns and functions of COUP-TFs are conserved in other animals. In the rat retina, $\mathrm{M}$-opsin and S-opsin are expressed homogeneously through- 
out the retina, whereas S-opsin is present in only $5-10 \%$ of cones (supplemental Fig. S6A, available at www.jneurosci.org as supplemental material). We found that, similar to the mouse retina, COUP-TFI expression decreased from the ventral to the dorsal side in the rat retina during embryogenesis (supplemental Fig. $\mathrm{S} 6 \mathrm{C}$, available at www.jneurosci.org as supplemental material). In the adult rat retina, we observed that COUP-TFI was expressed in the cells of the GCL and INL and that it maintained its expression gradient (supplemental Fig. S6 B, available at www.jneurosci. org as supplemental material). COUP-TFII was detected in the dorsal retinas of rat embryos, which was similar to our findings in the dorsal mouse retina; moreover, we observed weak but clear COUP-TFII expression in other parts of the retina (supplemental Fig. S6C, two-headed arrow, available at www.jneurosci.org as supplemental material). Based on these findings, we hypothesize that the presence of both COUP-TFI and COUP-TFII throughout the retina in the rat embryos may contribute to the suppression of S-opsin in cone cells, whereas the presence of COUP-TFII on only the dorsal side of the retina in mouse embryos leads to the suppression of S-opsin in dorsal cone cells. Although opsin expression pattern varies by species, COUP-TFs may commonly regulate the formation of opsin expression patterns. Additional elucidation of the molecular mechanism of opsin patterning in mouse retina will shed light on the formation of the human fovea, in which $\mathrm{M}$-opsin and L-opsin are exclusively expressed.

\section{References}

Applebury ML, Antoch MP, Baxter LC, Chun LL, Falk JD, Farhangfar F, Kage K, Krzystolik MG, Lyass LA, Robbins JT (2000) The murine cone photoreceptor: a single cone type expresses both $\mathrm{S}$ and $\mathrm{M}$ opsins with retinal spatial patterning. Neuron 27:513-523.

Applebury ML, Farhangfar F, Glösmann M, Hashimoto K, Kage K, Robbins JT, Shibusawa N, Wondisford FE, Zhang H (2007) Transient expression of thyroid hormone nuclear receptor TRbeta2 sets S opsin patterning during cone photoreceptor genesis. Dev Dyn 236:1203-1212.

Bardoux P, Zhang P, Flamez D, Perilhou A, Lavin TA, Tanti JF, Hellemans K, Gomas E, Godard C, Andreelli F, Buccheri MA, Kahn A, Le MarchandBrustel Y, Burcelin R, Schuit F, Vasseur-Cognet M (2005) Essential role of chicken ovalbumin upstream promoter-transcription factor II in insulin secretion and insulin sensitivity revealed by conditional gene knockout. Diabetes 54:1357-1363.

Bruhn SL, Cepko CL (1996) Development of the pattern of photoreceptors in the chick retina. J Neurosci 16:1430-1439.

Chen S, Wang QL, Nie Z, Sun H, Lennon G, Copeland NG, Gilbert DJ, Jenkins NA, Zack DJ (1997) Crx, a novel Otx-like paired-homeodomain protein, binds to and transactivates photoreceptor cell-specific genes. Neuron 19:1017-1030.

Dartnall HJ, Bowmaker JK, Mollon JD (1983) Human visual pigments: microspectrophotometric results from the eyes of seven persons. Proc R Soc Lond B Biol Sci 220:115-130.

Fei Y (2003) Development of the cone photoreceptor mosaic in the mouse retina revealed by fluorescent cones in transgenic mice. Mol Vis 9:31-42.

Fjose A, Nornes S, Weber U, Mlodzik M (1993) Functional conservation of vertebrate seven-up related genes in neurogenesis and eye development. EMBO J 12:1403-1414.

Furuta Y, Hogan BL (1998) BMP4 is essential for lens induction in the mouse embryo. Genes Dev 12:3764-3775.

Furuta Y, Lagutin O, Hogan BL, Oliver GC (2000) Retina- and ventral forebrain-specific Cre recombinase activity in transgenic mice. Genesis 26:130-132.

Gallais R, Demay F, Barath P, Finot L, Jurkowska R, Le Guével R, Gay F, Jeltsch A, Métivier R, Salbert G (2007) Deoxyribonucleic acid methyl transferases $3 \mathrm{a}$ and $3 \mathrm{~b}$ associate with the nuclear orphan receptor COUPTFI during gene activation. Mol Endocrinol 21:2085-2098.

Hyatt GA, Schmitt EA, Marsh-Armstrong N, McCaffery P, Dräger UC, Dowling JE (1996) Retinoic acid establishes ventral retinal characteristics. Development 122:195-204.

Jean D, Ewan K, Gruss P (1998) Molecular regulators involved in vertebrate eye development. Mech Dev 76:3-18.
Jonk LJ, de Jonge ME, Pals CE, Wissink S, Vervaart JM, Schoorlemmer J, Kruijer W (1994) Cloning and expression during development of three murine members of the COUP family of nuclear orphan receptors. Mech Dev 47:81-97.

Koshiba-Takeuchi K, Takeuchi JK, Matsumoto K, Momose T, Uno K, Hoepker V, Ogura K, Takahashi N, Nakamura H, Yasuda K, Ogura T (2000) Tbx5 and the retinotectum projection. Science 287:134-137.

Lee CT, Li L, Takamoto N, Martin JF, Demayo FJ, Tsai MJ, Tsai SY (2004) The nuclear orphan receptor COUP-TFII is required for limb and skeletal muscle development. Mol Cell Biol 24:10835-10843.

Li A, Zhu X, Brown B, Craft CM (2003) Gene expression networks underlying retinoic acid-induced differentiation of human retinoblastoma cells. Invest Ophthalmol Vis Sci 44:996-1007.

Li H, Wagner E, McCaffery P, Smith D, Andreadis A, Dräger UC (2000) A retinoic acid synthesizing enzyme in ventral retina and telencephalon of the embryonic mouse. Mech Dev 95:283-289.

Lin YP, Ouchi Y, Satoh S, Watanabe S (2009) Sox2 plays a role in the induction of amacrine and Mueller glial cells in mouse retinal explant culture. Invest Ophthalmol Vis Sci 50:68-74.

Liu J, Wilson S, Reh T (2003) BMP receptor $1 \mathrm{~b}$ is required for axon guidance and cell survival in the developing retina. Dev Biol 256:34-48.

Lu XP, Salbert G, Pfahl M (1994) An evolutionary conserved COUP-TF binding element in a neural-specific gene and COUP-TF expression patterns support a major role for COUP-TF in neural development. Mol Endocrinol 8:1774-1788.

Marsh-Armstrong N, McCaffery P, Gilbert W, Dowling JE, Dräger UC (1994) Retinoic acid is necessary for development of the ventral retina in zebrafish. Proc Natl Acad Sci U S A 91:7286-7290.

McCaffery P, Wagner E, O’Neil J, Petkovich M, Dräger UC (1999) Dorsal and ventral rentinoic territories defined by retinoic acid synthesis, breakdown and nuclear receptor expression. Mech Dev 85:203-214.

Mic FA, Molotkov A, Fan X, Cuenca AE, Duester G (2000) RALDH3, a retinaldehyde dehydrogenase that generates retinoic acid, is expressed in the ventral retina, otic vesicle and olfactory pit during mouse development. Mech Dev 97:227-230.

Mlodzik M, Hiromi Y, Weber U, Goodman CS, Rubin GM (1990) The Drosophila seven-up gene, a member of the steroid receptor gene superfamily, controls photoreceptor cell fates. Cell 60:211-224.

Murali D, Yoshikawa S, Corrigan RR, Plas DJ, Crair MC, Oliver G, Lyons KM, Mishina Y, Furuta Y (2005) Distinct developmental programs require different levels of Bmp signaling during mouse retinal development. Development 132:913-923.

Naka H, Nakamura S, Shimazaki T, Okano H (2008) Requirement for COUP-TFI and II in the temporal specification of neural stem cells in CNS development. Nat Neurosci 11:1014-1023.

Ng L, Hurley JB, Dierks B, Srinivas M, Saltó C, Vennström B, Reh TA, Forrest D (2001) A thyroid hormone receptor that is required for the development of green cone photoreceptors. Nat Genet 27:94-98.

Peng GH, Chen S (2007) Crx activates opsin transcription by recruiting HAT-containing co-activators and promoting histone acetylation. Hum Mol Genet 16:2433-2452.

Pereira FA, Qiu Y, Zhou G, Tsai MJ, Tsai SY (1999) The orphan nuclear receptor COUP-TFII is required for angiogenesis and heart development. Genes Dev 13:1037-1049.

Qiu Y, Cooney AJ, Kuratani S, DeMayo FJ, Tsai SY, Tsai MJ (1994) Spatiotemporal expression patterns of chicken ovalbumin upstream promotertranscription factors in the developing mouse central nervous system: evidence for a role in segmental patterning of the diencephalon. Proc Natl Acad Sci U S A 91:4451-4455.

Qiu Y, Pereira FA, DeMayo FJ, Lydon JP, Tsai SY, Tsai MJ (1997) Null mutation of mCOUP-TFI results in defects in morphogenesis of the glossopharyngeal ganglion, axonal projection, and arborization. Genes Dev 11:1925-1937.

Reid TW, Albert DM, Rabson AS, Russell P, Craft J, Chu EW, Tralka TS, Wilcox JL (1974) Characteristics of an established cell line of retinoblastoma. J Natl Cancer Inst 53:347-360.

Roberts MR, Hendrickson A, McGuire CR, Reh TA (2005) Retinoid X receptor (gamma) is necessary to establish the S-opsin gradient in cone photoreceptors of the developing mouse retina. Invest Ophthalmol Vis Sci 46:2897-2904.

Roberts MR, Srinivas M, Forrest D, Morreale de Escobar G, Reh TA (2006) Making the gradient: thyroid hormone regulates cone opsin expression in the developing mouse retina. Proc Natl Acad Sci U S A 103:6218-6223. 
Söderpalm A, Szél A, Caffé AR, van Veen T (1994) Selective development of one cone photoreceptor type in retinal organ culture. Invest Ophthalmol Vis Sci 35:3910-3921.

Srinivas M, Ng L, Liu H, Jia L, Forrest D (2006) Activation of the blue opsin gene in cone photoreceptor development by retinoid-related orphan receptor beta. Mol Endocrinol 20:1728-1741.

Suh JM, Yu CT, Tang K, Tanaka T, Kodama T, Tsai MJ, Tsai SY (2006) The expression profiles of nuclear receptors in the developing and adult kidney. Mol Endocrinol 20:3412-3420.

Szél A, Röhlich P, Caffé AR, van Veen T (1996) Distribution of cone photoreceptors in the mammalian retina. Microsc Res Tech 35:445-462.

Tabata Y, Ouchi Y, Kamiya H, Manabe T, Arai K, Watanabe S (2004) Retinal fate specification of mouse embryonic stem cells by ectopic expression of $\mathrm{Rx} / \mathrm{rax}$, a homeobox gene. Mol Cell Biol 24:4513-4521.

Takechi M, Kawamura S (2005) Temporal and spatial changes in the expression pattern of multiple red and green subtype opsin genes during zebrafish development. J Exp Biol 208:1337-1345.
Tang LS, Alger HM, Lin F, Pereira FA (2005) Dynamic expression of COUP TFI and COUP-TFII during development and functional maturation of the mouse inner ear. Gene Expr Patterns 5:587-592.

Trousse F, Esteve P, Bovolenta P (2001) Bmp4 mediates apoptotic cell death in the developing chick eye. J Neurosci 21:1292-1301.

Tsai SY, Tsai MJ (1997) Chick ovalbumin upstream promoter-transcription factors (COUP-TFs): coming of age. Endocr Rev 18:229-240.

Wikler KC, Szel A, Jacobsen AL (1996) Positional information and opsin identity in retinal cones. J Comp Neurol 374:96-107.

Yamamichi N, Yamamichi-Nishina M, Mizutani T, Watanabe H, Minoguchi S, Kobayashi N, Kimura S, Ito T, Yahagi N, Ichinose M, Omata M, Iba H (2005) The Brm gene suppressed at the post-transcriptional level in various human cell lines is inducible by transient HDAC inhibitor treatment, which exhibits antioncogenic potential. Oncogene 24:54715481.

Zhang XM, Yang XJ (2001) Temporal and spatial effects of Sonic hedgehog signaling in chick eye morphogenesis. Dev Biol 233:271-290. 